\title{
475748 - VENTILATORY MANAGEMENT IN NON-SELECTED PATIENTS WITH ARDS
}

\author{
Martin Lessard, $\mathbf{M D}^{1}$, Natasha Langis, $\mathbf{R R T}^{2}$, Niall Ferguson, $\mathbf{M D}^{3}$, Maureen \\ Meade, $\mathrm{MD}^{4}$, Alexis Turgeon, $\mathrm{MD}, \mathrm{MSc}^{1}$ \\ 1. Department of Anesthesia and Critical Care, CHAUQ (Hôpital Enfant-Jésus) - \\ Université Laval, Quebec City, QC, Canada \\ 2. Centre de Recherche, CHAUQ, Quebec City, QC, Canada \\ 3. Interdepartmental Divison of Critical Care Medicine, University Health Network, \\ Toronto, ON, Canada \\ 4. Department of Medicine, McMaster University, Hamilton, ON, Canada
}

Introduction: Mechanical ventilation is known to affect outcome in ARDS. Guidelines for ventilatory management have been published, but little is known about actual practice. The aim of this study was to describe ventilatory management in non-selected consecutive patients with ARDS in an academic centre.

Methods: This prospective observational cohort study was approved by the REB who did not require patient consent. Over a 12-month period, we enrolled all consecutive critically ill adult with ARDS according to American-European Consensus Conference in a single multidisciplinary tertiary intensive care unit with a long history of participation in ARDS trials. No trials were underway during this period of observation. According to a local guideline for low volume ventilation, initial tidal volume is set at $6 \mathrm{~mL} / \mathrm{kg}$ predicted body weight (PBW) and titrated down to target plateau pressure lower than $30 \mathrm{cmH}_{2} \mathrm{O}$, while PEEP and $\mathrm{FiO}_{2}$ are set according to the control arm of the Lung Open Ventilation Study.(1) However, management decisions are ultimately left to the attending intensivists who were not aware of the present study. Demographic data at baseline and outcome data were recorded. Morning mechanical ventilation and gas exchange data were recorded daily for the first seven days.

Results: Among the 37 patients cohort (age 54.8 \pm 17.4 , 54\% male), the most frequent risks factors for ARDS were sepsis/septic shock (73\%) and pneumonia (70\%). Mean APACHE II score was 23.1 \pm 7.6 and mean $\mathrm{PaO}_{2} / \mathrm{FiO}_{2}$ was $122.1 \pm 40.6$; these did not differ between survivors and non-survivors. Primary ventilation modes included: volume control +/- autoflow (30 patients), pressure regulated volume control (6 patients) and pressure control (1 patient). Mean expired tidal volume was $7.3 \pm 1.4 \mathrm{~mL} / \mathrm{kg}$ PBW (survivors 7.2 \pm 1.5 , non-survivors 7.3 \pm 1.3 ). $\mathrm{PEEP}$ was $9.7 \pm 3.7 \mathrm{cmH}_{2} \mathrm{O}$ (highest 22 $\mathrm{cmH}_{2} \mathrm{O}$ ). Mean plateau pressure was $27.4 \pm 5.8 \mathrm{cmH}_{2} \mathrm{O}$ and was slightly in survivors

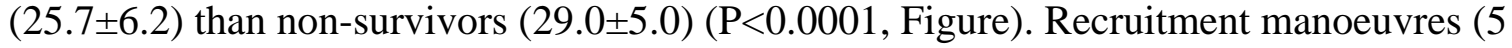
patients) and prone positioning (1 patient) were uncommon. ICU and hospital mortalities were $51 \%$.

Discussion: In this academic unit, uptake of an established low tidal volume ventilation strategy for ARDS has been moderate, PEEP levels are moderately high, and use of rescue therapies is minimal. The relatively high mortality rate may be related primarily to the high rate of sepsis as the underlying etiology of ARDS.

References: 1. JAMA 2008;299:637-645 


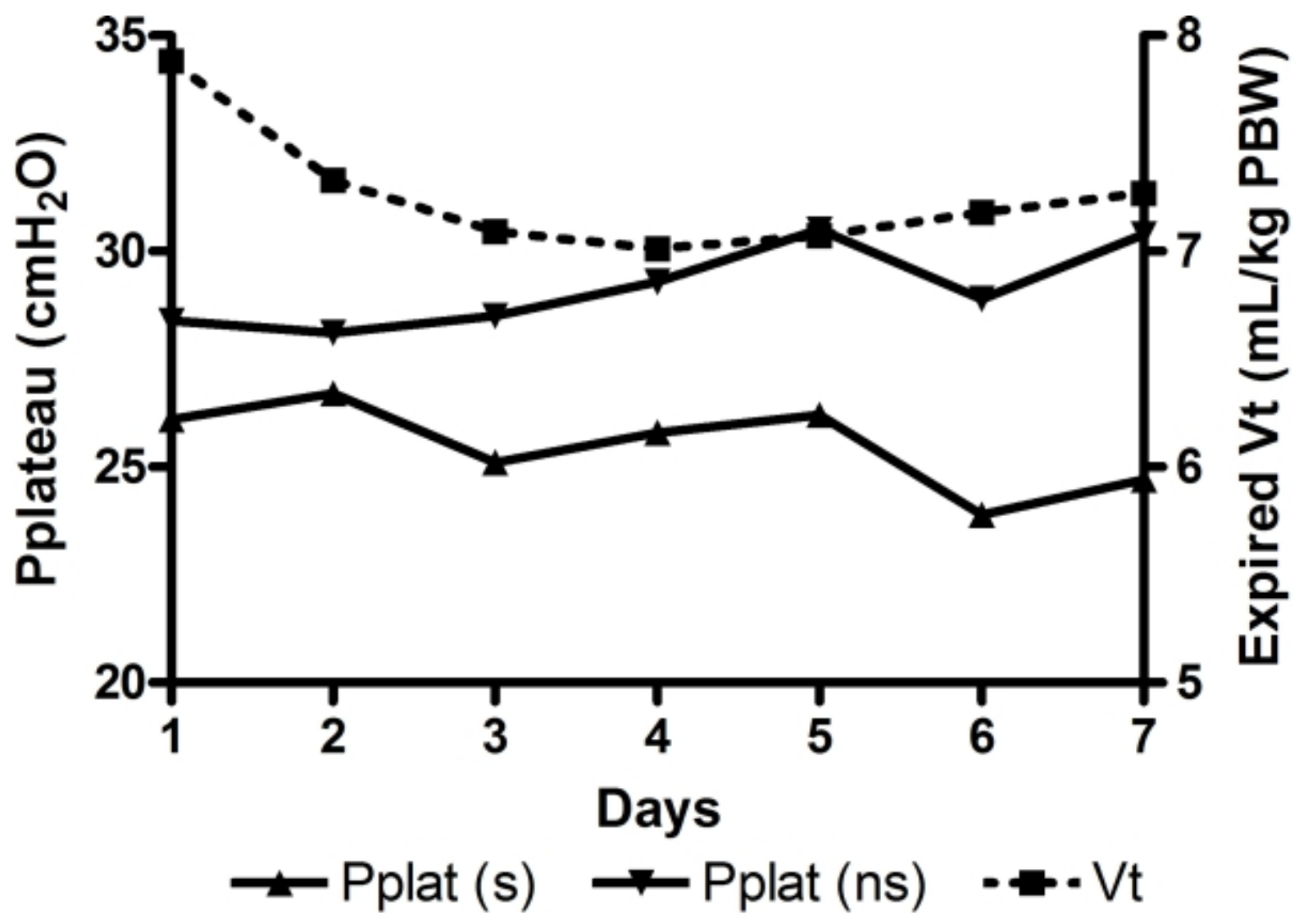

Mean expired tidal volume (Vt) for all patients. Mean plateau pressure (Pplat) was lower for survivors (s) than for non-survivors (ns) $(\mathrm{P}<0.0001)$ 